\title{
CORRECTION
}

\section{Correction: Management and outcomes of the small pupil in cataract surgery: iris hooks, Malyugin ring or phenylephrine?}

Shafi Balal (D), Ahmed Said Jbari (D), Rynda Nitiahpapand, Erica Cook, Wasim Akhtar, Nizar Din and Anant Sharma

(c) The Author(s), under exclusive licence to The Royal College of Ophthalmologists 2021

Eye (2021) 35:2909; https://doi.org/10.1038/s41433-021-01689-6

Correction to: Eye https://doi.org/10.1038/s41433-020-01277-0

The original article has bee corrected.

Unfortunately, the spelling of the author's name Rynda Nitiahpapand was incorrect. 